\begin{tabular}{|c|c|c|}
\hline & Int.J.Curr.Microbiol.App.Sci (2021) 10(11): 43-47 & \\
\hline & $\begin{array}{l}\text { International Journal of Current Microbiology and Applied Sciences } \\
\text { ISSN: 2319-7706 Volume } 10 \text { Number } 11 \text { (2021) } \\
\text { Journal homepage: http://www.ijcmas.com }\end{array}$ & 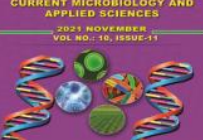 \\
\hline $\begin{array}{l}\text { EXCELLENT } \\
\text { PUBLISHERS }\end{array}$ & & \\
\hline
\end{tabular}

Original Research Article

https://doi.org/10.20546/ijcmas.2021.1011.006

\title{
Kinetics of Maternal Derived Antibody Status against Canine Distemper in Pups
}

\author{
Bhambhani Mitali Inder ${ }^{1}$, M. Asok Kumar ${ }^{1 *}$, A. Ramesh ${ }^{2}$, N. R. Senthil ${ }^{1}$, \\ K. Srinivas ${ }^{3}$, T. Devi ${ }^{1}$ and P. Revathi ${ }^{1}$ \\ ${ }^{1}$ Department of Veterinary Preventive Medicine, Madras Veterinary College, \\ TANUVAS, Chennai, Tamil Nadu, India \\ ${ }^{2}$ Vaccine Research Centre - Viral Vaccines, Centre for Animal Health Studies, TANUVAS, \\ Chennai, Tamil Nadu, India \\ ${ }^{3}$ Indian Immunologicals Ltd. (NDDB), Hyderabad, India \\ *Corresponding author
}

\section{A B S T R A C T}

Keywords

Canine Distemper-

MDA- SNT and

ELISA- Puppies

immunization

Article Info

Received:

05 October 2021

Accepted:

30 October 2021

Available Online:

10 November 2021
Sixty-four sera samples were collected from 25- and 45-days old puppies [16 puppies each from vaccinated (Group I) and unvaccinated (Group II) dam] brought to Immunization Unit, Madras Veterinary College Teaching Hospital, Chennai. The samples were subjected to functional antibody assay (SNT) and commercially available Indirect ELISA to know the kinetics of maternal derived antibody (MDA) against canine distemper. The mean MDA titre in Group I puppies were found as $4.38 \pm 1.41$ and the ELISA titre were $30-60$ and 10-30 AU on 25 and 45 days of age respectively whereas the Group II (MDA-UV) had titre value of0.33 \pm 0.60 and 0 by SNT $\left(\mathrm{SN}_{50}\right)$ and $\leq 10$ and $\leq$ 3 AU by Indirect ELISA on 25 and 45 days of pups respectively. Though the statistical analysis (Mann-Whitney test) revealed a significant difference $(\mathrm{P}<0.01)$ between MDA of two groups with none of the group member had required protective titre, this study strongly suggests that the dogs aged more than 4 weeks needs to be immunized against CDV in endemic region in view of eliciting protective titre at earlier with a view of avoiding window period of susceptibility between 25 and 45 days of age.

\section{Introduction}

Canine distemper $(\mathrm{CD})$ is a highly infectious as well as contagious acute fatal viral disease and is second only to rabies when it comes to case fatality rates in dogs (Degene and Zebene, 2019). It is caused by canine distemper virus (CDV) belonging to the genus Morbillivirus of the family Paramyxoviridae (Deem et al., 2000). The disease gets spread 
ubiquitous in dogs and its incidence is alarming nowadays even after major coverage of pet dogs with immunization and lacking attention on community owned and stray dogs. Although CDV exhibits a tremendous diversity in its species tropism, domestic and feral dogs are the primary reservoir species in most locations with its potential spillover of pathogens. Since there is no curative treatment for canine distemper infection, it is imperative that immunization of these animals is the most practical and effective method to tackle this deadly disease in order to curb its spread. Though the canine distemper vaccine is a core vaccine, the current vaccination practice is not adequate to achieve the $95 \%$ coverage that is necessary to control CDV by developing population immunity (Loots et al., 2017). Moreover, many incidences of canine distemper have been reported below 35 days old pups and even in vaccinated dogs at recent times (Infectious Disease Unit, Madras Veterinary College).

Generally, the presence of maternal derived antibodies (MDA) at the time of primary vaccination is the leading cause of vaccination failure in puppies. MDA is very useful for the pups at an early age where the passive transfer of MDA to individual pup is largely (90-95\%) dependent on colostrum feeding and litter size since chorio-endothelial type of placenta allow the MDA to pup between 3-10 percent. There has also been a general opposition by Veterinary Practitioners for early vaccination of pups owing to the concerns regarding the adverse effects of MDA during vaccination (De Cramer et al., 2011). The current WSAVA Vaccination Guidelines Group (VGG) recommends that the initial core vaccination in pups is to be done at 6-8 weeks of age, then every 2-4 weeks until 16 weeks of age or older in order to overcome the immunization failure due to maternal immunity (Day et al., 2016). However, several cases of canine distemper have been reported in puppies despite the recommended guidelines is being adapted. Since there is no enough regional data available on the waning status of maternal immunity against canine distemper in tropical countries like India, the current study has been designed to gain a better understanding on the MDA status in naive puppies from vaccinated as well as unvaccinated dam.

\section{Materials and Methods}

A Tissue Culture Monolayer (TC monoDMEM) medium, Canine Distemper Challenge Virus Standard (Onderstepoort) strain and Signaling Lymphocytic Activation Molecule (SLAM) transfected Vero cells maintained at Indian Immunologicals Ltd. (IIL), National Dairy Development Board (NDDB), Hyderabad were utilized for this study. Commercially available ELISA kits were procured from European Veterinary Laboratory, Netherlands for the assessment of IgG antibodies against $\mathrm{CD}$ in the serum samples.

A total of 64 blood samples were collected from 32 puppies at the age of 25-28 days and then again at 45 days of age for ascertaining the waning status of maternal derived antibody (MDA) against canine distemper.

The puppies were divided into two groups of 16 animals each (Statistical Power Analysis), where Group I and Group II consisted of puppies born of vaccinated and unvaccinated dams respectively. Blood samples were collected from the cephalic vein of each dog prior to priming and after immunization and transferred to a sterile clot activator plain vacutainer for serum separation. The collected blood samples were then centrifuged at 5000 rpm for $5 \mathrm{~min}$. for separation of the serum and then stored at $-20^{\circ} \mathrm{C}$ until were subjected to Serum Neutralization Test (SNT) as well as Enzyme-linked Immunosorbent Assay 
(ELISA). The neutralization test was carried out as per the standard testing protocol followed by Indian Immunologicals Ltd., Hyderabad and the ELISA was performed according to the commercial kit manufacturer's instructed protocol.

\section{Results and Discussion}

The Serum Neutralization $\left(\mathrm{SN}_{50}\right)$ antibody titer of greater than or equal to 32 and/or the Arbitrary Unit of $\geq 90$ AU by ELISA is considered protective against canine distemper (IRS, IIL Hyderabad \& EVL, Netherland) and serum neutralization titers of at least 1:16 to 1:20 correlate with protection after vaccination while titers of $1: 100$ or more correlate with protection in puppies that have received maternal antibodies (Greene and Appel, 2006).

The present study results showed that the mean MDA titre of puppies from vaccinated Group I (MDA-V) were estimated to be $4.38 \pm$ 1.41 and $0.32 \pm 0.41 \mathrm{SN}_{50}$ and the ELISA titre were found as 30- 60 and 10-30 AUon 25 and 45 days of age respectively. Whereas the MDA titre value of Group II (MDA-UV) were $0.33 \pm 0.60$ and 0 by SNT $\left(\mathrm{SN}_{50}\right)$ and $\leq 10$ and $\leq 3$ by Indirect ELISA were noticed on 25 and 45 days of pups respectively (Table $1 \&$ Fig 1). The MDA titre value from all pups by both these tests were found to be far below the level of protective titre and all SNT values were falling below $6\left(<6 \mathrm{SN}_{50}\right)$ at 25 as well as 45 days of age and waning of MDA is noticed to almost zero level by $45^{\text {th }}$ day.

Similarly, the ELISA titre value producing inconclusive level of protection on $25^{\text {th }}$ days of age and falling to negative protective titre ( $\leq 30 \mathrm{AU})$ at 45 days of age in pups from vaccinated groups whereas none of the pups from unvaccinated dam i.e. Group II showed the protective MDA level on 25 as well as 45 days of age. Maternally derived immunity plays a major role in determining the priming of pups against canine distemper since it is highly infectious causing mortality and considered the primary cause of vaccine failure in young dogs. Though the MDA offers protection against infection, it is not complete as it is in dogs that have both humoral and cell mediated immunity. This study finding is compliance with Gray et al., (2012) who stated that protective antibody titre of MDA against CD got decreased rapidly as its halflife is below 8.5 days and render puppies susceptible to early infection. In our study, we also found that the colostral antibody is although vital for protection of puppies for the first weeks of their life, it creates window period of susceptibility to CDV infection between 25 and 45 days of age as MDA gets complete waning and the current immunization practice commence from 6 weeks of life in India with exception of priming the puppies with bivalent vaccine (DP) at 4 weeks of age by few private practitioners. This is well accordance with the report of Greene and Appel (2006) who stated when the titre of passively acquired SN CDV is too low $\left(\leq 6 \mathrm{SN}_{50}\right)$, the pup could be easily susceptible to CDV infection.

It makes customary to check MDA waning dynamics in puppies against canine distemper at regional level in order to ensure subsequent protection by priming with vaccine when maternal antibody levels wane although it is recommended to vaccinate puppies repeatedly between 6 and 16 weeks of age. Puppies that have lost their maternal antibody are predisposed in regions where vaccination is performed, but occasionally disease occurs in older, vaccinated dogs. Canine distemper also occurs in regions where vaccination of dogs is not performed or is poorly timed. 
Table.1 Maternal Derived Antibody status of pups against CDV

\begin{tabular}{|c|c|c|c|c|}
\hline \multirow{2}{*}{ Test Name } & \multicolumn{2}{|c|}{ Group I (MDA-V) } & \multicolumn{2}{c|}{ Group II (MDA-UV) } \\
\cline { 2 - 5 } & $25^{\text {th }}$ day & $45^{\text {th }}$ day & $25^{\text {th }}$ day & $45^{\text {th }}$ day \\
\hline SNT $\left(\mathbf{S N}_{\mathbf{5 0}}\right.$ ) & $4.38 \pm 1.41$ & $0.32 \pm 0.41$ & $0.33 \pm 0.60$ & 0 \\
\hline ELISA (AU) & $30-60$ & $10-30$ & $\leq 10$ & $\leq 3$ \\
\hline
\end{tabular}

n=16 each for Group I \&II

Fig.1

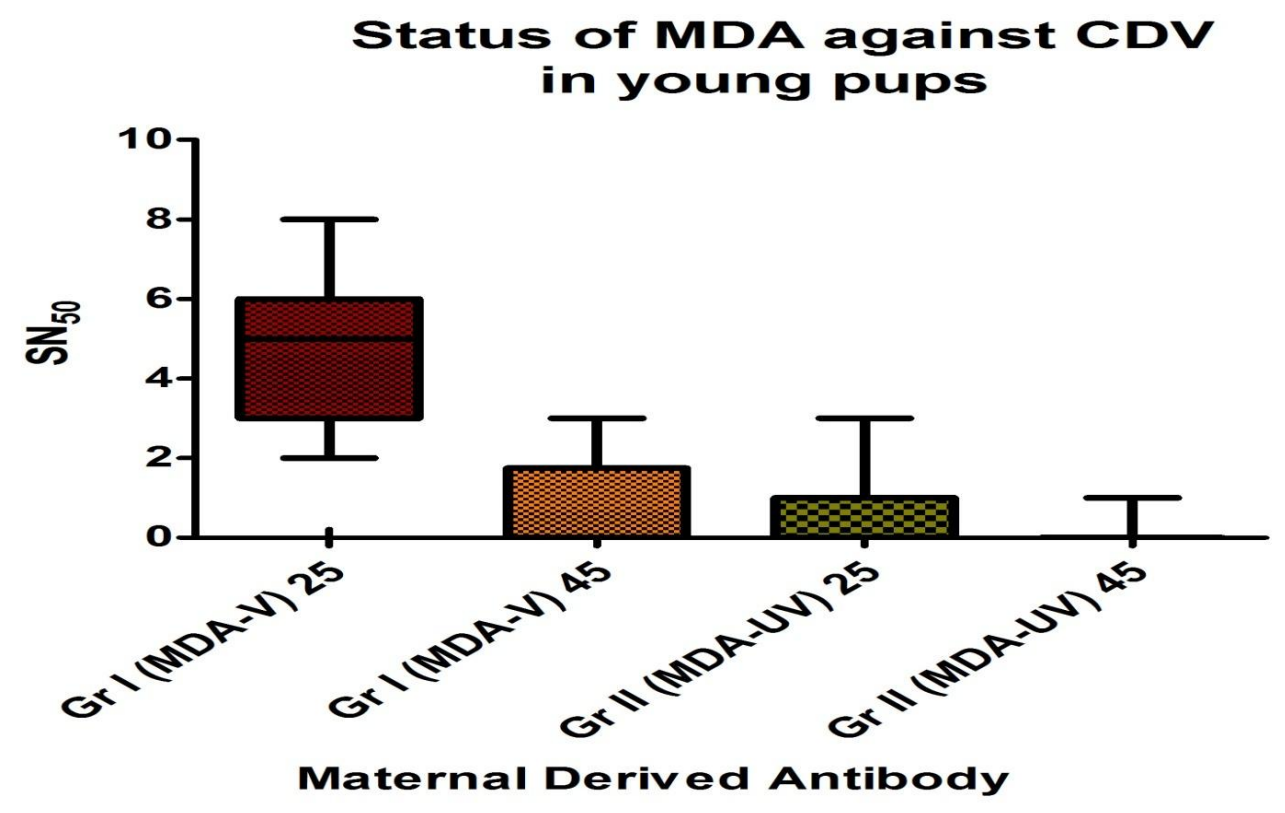

This study has shown that the dynamic waning of maternal derived antibodies varies with number of litters born to dam and gap between immunization of dam and littering. When there is high number litter size with long gap of dam's vaccination, then the MDA is waning too shortly within 5 weeks of age compared to previous studies where the MDA was lasting up to 6 weeks.

The present study exposes waning kinetics of MDA against Canine Distemper in Indian subcontinent tropical region and advocates the advancing of immunization of puppies with bivalent vaccines (DP) at 4 weeks of age where the question of MDA interference is minimum or it can be overcome by offering little higher dose of Modified Live Virus titre $\left(\mathrm{CCID}_{50}\right)$ during priming of pups.

\section{Acknowledgement}

We would like to thank Director of Clinics, Tamil Nadu Veterinary and Animal Sciences University and Professor and Head, Department of Clinics, Madras Veterinary College for permitting to collect samples from Infectious Disease and Immunization Unit, Madras Veterinary College Teaching Hospital, Chennai, Tamil Nadu and Dr. K. Anandhakumar, Managing Director, Indian Immunologicals, NDDB, Hyderabad for granting permission to carry out the partial work. We also thank Dr. Santhosh Gadgae, General Manager (Production) and Mrs. Neelima, Manager (Quality Control) for rendering their help during the study period. 
References

Day, M. J., Horzinek, M. C., Schultz, R. D. and Squires, R. A. 2016. Vaccination Guidelines Group (VGG) of the World Small Animal Veterinary Association (WSAVA). WSAVA Guidelines for the vaccination of dogs and cats. $J$. Small Anim. Pract., 57(1): E1-E45.

De Cramer, K. G., Stylianides, E. and van Vuuren, M. 2011. Efficacy of vaccination at 4 and 6 weeks in the control of canine parvovirus. Veterinary microbiology, 149(1-2): 126-132.

Deem, S. L., Spelman, L. H., Yates, R. A. and Montali, R. J. 2000. Canine distemper in terrestrial carnivores: a review. $J$ Zoo Wildl Med, 31(4): 441-51.

Degene, B., and Zebene, M., 2019. Canine Distemper, A Review. Int. J. Adv. Res. Biol. Sci., 6(7): 12-19.

Dorji, T., Tenzin, T., Tenzin, K., Tshering, D., Rinzin, K., Phimpraphai, W. and de
Garine-Wichatitsky, M. 2020. Seroprevalence and risk factors of canine distemper virus in the pet and stray dogs in Haa, western Bhutan. BMC Vet Res, 16(1): 135.

Gray, L. K., Crawford, P. C., Levy, J. K. and Dubovi, E. J. 2012. Comparison of two assays for detection of antibodies against canine parvovirus and canine distemper virus in dogs admitted to a Florida animal shelter. J. Am. Vet. Med. Asso. 240 (9): 1084-1087.

Greene, C. E and Apple, M. J. 2006. Canine Distemper. In: Infectious Diseases of the Dog and Cat, $3^{\text {rd }}$ Edit, C. E. Greene, Ed., Saunders Elsevier, St. Louis, Missouri, pp. 24-41.

Loots, A. K., Mitchell, E., Dalton, D. L., Kotzé, A. and Venter E. H. 2017. Advances in canine distemper virus pathogenesis research: A wildlife perspective. J Gen Virol, 98(3): 311321.

\section{How to cite this article:}

Bhambhani Mitali Inder, M. Asok Kumar, A. Ramesh, N. R. Senthil, K. Srinivas, T. Devi and Revathi, P. 2021. Kinetics of Maternal Derived Antibody Status against Canine Distemper in Pups. Int.J.Curr.Microbiol.App.Sci. 10(11): 43-47. doi: https://doi.org/10.20546/ijcmas.2021.1011.006 